\title{
Phylogenetic and functional conservation of the NKR-P1F and NKR-P1G receptors in rat and mouse
}

\author{
Lise Kveberg • Ke-Zheng Dai • Marit Inngjerdingen • \\ Colin G. Brooks • Sigbjørn Fossum • John T. Vaage
}

Received: 19 October 2010 /Accepted: 17 February 2011 /Published online: 16 March 2011

(C) The Author(s) 2011. This article is published with open access at Springerlink.com

\begin{abstract}
Two clusters of rat Nkrpl genes can be distinguished based on phylogenetic relationships and functional characteristics. The proximal (centromeric) cluster encodes the well-studied NKR-P1A and NKR-P1B receptors and the distal cluster, the largely uncharacterized, NKR-P1F and NKR-P1G receptors. The inhibitory NKR-P1G receptor is expressed only by the Ly49s $3^{+} \mathrm{NK}$ cell subset as detected by RT-PCR, while the activating NKR-P1F receptor is detected in both $\mathrm{Ly}_{49 \mathrm{~s} 3}{ }^{+}$and NKR-P1B ${ }^{+} \mathrm{NK}$ cells. The mouse NKR-P1G ortholog is expressed by both NKR${\mathrm{P} 1 \mathrm{D}^{-} \text {and NKR-P1D }}^{+} \mathrm{NK}$ cells in C57BL/6 mice. The rat and mouse NKR-P1F and NKR-P1G receptors demonstrate a striking, cross-species conservation of specificity for $\mathrm{Clr}$ ligands. NKR-P1F and NKR-P1G reporter cells reacted with overlapping panels of tumour cell lines and with cells transiently transfected with rat $\mathrm{Clr} 2, \mathrm{Clr} 3, \mathrm{Clr} 4, \mathrm{Clr} 6$ and $\mathrm{Clr} 7$ and mouse Clrc, Clrf, Clrg and Clrd/x, but not with Clr11 or Clrb, which serve as ligands for NKR-P1 from the proximal cluster. These data suggest that the conserved
\end{abstract}

L. Kveberg · K.-Z. Dai • M. Inngjerdingen · J. T. Vaage $(\bowtie)$

Department of Immunology,

Oslo University Hospital, Rikshospitalet and University of Oslo, Oslo, Norway

e-mail: j.t.vaage@medisin.uio.no

C. G. Brooks

Institute of Cell and Molecular Biosciences,

University of Newcastle,

Newcastle, UK

S. Fossum

Department of Anatomy, Institute of Basic Medical Sciences,

University of Oslo,

Oslo, Norway
NKR-P1F and NKR-P1G receptors function as promiscuous receptors for a rapidly evolving family of $\mathrm{Cl}$ ligands in rodent NK cells.

Keywords Comparative Immunology · Killer cell lectinlike receptor $\cdot$ NK cells $\cdot$ Rodent

\section{Introduction}

NK cells express several multi-gene families of killer cell lectin-like receptors (KLR) encoded by the NK gene complex (NKC), which is located on rat chromosome 4 and mouse chromosome 6 (Flornes et al. 2010; Yokoyama and Plougastel 2003). These include the NKR-P1, NKG2 and Ly49 families of receptors, encoded from the centromeric, central and telomeric parts of the $\mathrm{NKC}$, respectively. Rat Ly49 molecules are reactive with MHC molecules from the classical class Ia $(R T 1-A)$ and non-classical class $\mathrm{Ib}(R T 1-C E)$ regions (Naper et al. 1999, 2005). In the mouse, NKG2 together with the partner CD94 bind the class Ib molecule Qa ${ }^{\mathrm{b}}$ (Vance et al. 1998), and in the rat tetramers of RT.BM1, the rat ortholog of mouse Qa $1^{\mathrm{b}}$ stain a subset of rat NK cells low in Ly49 receptors but enriched for $\mathrm{Nkg} 2 \mathrm{a} / \mathrm{c}$ expression (Kveberg et al. 2010).

The NKR-P1 receptors were among the first KLRs to be discovered. Only in recent years were they shown to bind members of another NKC family, the C-type lectin-related (Clr) molecules (Carlyle et al. 2004; Iizuka et al. 2003). Four functional NKR-P1 molecules exist in Brown Norway (BN) strain rats, which are encoded by two pairs of genes located in the proximal (centromeric) part of the NKC and separated by a stretch of approximately $500 \mathrm{~kb}$ harbouring 
seven full-length $\mathrm{Clr}$ genes (Kveberg et al. 2009). The most centromeric cluster encodes the well-characterized NKRP1A and NKR-P1B receptors. NKR-P1A is an activation receptor that has been used as the prototypic marker for rat NK cells, and it is also expressed by some T cells (Appasamy et al. 1996; Giorda et al. 1990). NKR-P1B is an inhibitory receptor that exists in two divergent variants (Kveberg et al. 2009; Voigt et al. 2007). The PVG strain allele is expressed by a major subset of NK cells expressing few $\mathrm{Ly} 49$ genes but enriched for $\mathrm{Nkg} 2 \mathrm{a} / \mathrm{c}$ transcripts. NKR$\mathrm{P}_{1 \mathrm{~B}^{+}} \mathrm{NK}$ cells are fully functional but are less responsive to IL-2 stimulation than the complementary population of Ly49s $3^{+}$(Ly49 stimulatory receptor 3 ) NK cells and are unable to mediate alloreactivity against normal lymphoblast target cells (Kveberg et al. 2006a, 2010). One of the NKR$\mathrm{P} 1 \mathrm{~B}$ variants has been shown to mediate protection against cytomegalovirus (CMV) infection in vivo (Voigt et al. 2007). Both NKR-P1A and NKR-P1B bind the most distal Clr member, Clr11, and ligation leads to either activation or inhibition of NK cell cytotoxicity (Kveberg et al. 2006a, 2009; Voigt et al. 2007).

Much less is known about the telomeric Nkrpl cluster encoding the NKR-P1F and NKR-P1G receptors and their orthologs in mice. NKR-P1F and NKR-P1G react with an overlapping panel of $\mathrm{Clr}$ molecules, but not with Clr11 (Kveberg et al. 2009). NKR-P1F mRNA has been detected in NK cells and some NKR-P1A $\mathrm{A}^{+} \mathrm{T}$ cells (Appasamy et al. 1996). Its mouse equivalent (mNKR-P1F) has been reported to react with Clrg (Clec2i) (Iizuka et al. 2003) and Clrx (Aust et al. 2009), the latter being encoded by a gene that maps in the same position as a fragment previously named Clrd (Plougastel et al. 2001), also known as Clec2g and Ocilrp1. mNKR-P1F is expressed by all NK cells, but not by $\mathrm{T}$ cells, in C57BL/6 mice as judged by staining with a novel mAb (Aust et al. 2009). Its activation potential is questionable, however, since it does not enhance cytotoxicity or IFN- $\gamma$ production upon crosslinking. mNKR-P1G remains uncharacterized. It was considered a pseudogene (Carlyle et al. 2006), but we isolated a full-length cDNA clone based on its homology with the rat gene (accession number DQ113419). In the present study, we show that the NKR-P1F and NKR-P1G receptors are xenoreactive, with closely related expression profiles and Clr ligand-binding characteristics in mice and rats.

\section{Materials and methods}

Cell lines and animals

Animals were housed in compliance with institutional guidelines and sacrificed at 8-12 weeks of age. PVG-
$R T 7^{b}$ rats possess a CD45 allotype (RT7.2) but are otherwise used interchangeably with the standard PVG strain (RT7.1) and were maintained at the Institute of Basic Medical Sciences, University of Oslo. Albino Oxford (AO) rats were from Harlan U.K., C57Bl/6 mice from Taconic (Denmark) and Harlan Olac (U.K.), and BALB/c/Sca mice were from NOVA SCB. The following cell lines were used: cc531s (rat colon carcinoma), RNK-16 (rat NK cell leukaemia), R2 (rat macrophage), YB2/0 (rat B cell myeloma), NS0 (mouse myeloma), EL-4 and YAC-1 (mouse T cell lymphomas), P388.D1 (mouse macrophagelike lymphoma), P815 (mouse mastocytoma), Ltk (mouse fibroblasts), RMA-S (mouse lymphoma with antigenprocessing defect), RAW 264.7 (mouse leukemic monocyte macrophage cell line) and 293T (human kidney fibroblast). Cell lines were maintained in complete RPMI (cRPMI; RPMI 1640 supplemented with $25 \mathrm{mM}$ HEPES, 10\% FBS, $1 \mathrm{mM}$ MEM sodium pyruvate, $5 \times 10^{-5} \mathrm{M} 2$-ME and antibiotics). The BWN3G reporter cell line (Kveberg et al. 2009) was maintained in cRPMI supplemented with $0.5 \mathrm{mg} / \mathrm{mL}$ of hygromycin B (Invitrogen, CA).

\section{Semi-quantitative PCR}

cDNA was generated from NKR-P1B ${ }^{+} \mathrm{Ly} 49 \mathrm{~s} 3^{-}$and NKR$\mathrm{P} 1 \mathrm{~B}^{-}$Ly $493^{+}$single-positive CD3 ${ }^{-}$NKR-P1A ${ }^{+}$NK cells from spleens of PVG- $R T 7^{b}$ rats and from NKR-P1D ${ }^{+}$and NKR-P1D ${ }^{-}$splenic NK cells $\left(C D 3^{-}{ }^{-}\right.$KR-P1C ${ }^{+}$) from C57BL/6 mice, obtained by sorting on a FACSAria by Trizol extraction, MMLV reverse transcriptase (Promega) and random hexamer primers (Fermentas). Semiquantitative polymerase chain reaction (PCR) on three tenfold dilutions of cDNA was performed by GoTaq polymerase (Promega), using the following forward (F) and reverse (R) primers: rat Nkrpla, 5'-CCTCAGTT TAAAGCCATCCAAGAC-3' (F) and 5'-CACTCGG CATGGCTCCACTGAT-3' (R); rat Nkrp $1 b, 5^{\prime}$-AGCA CAAGTCACCTCCATCTCT-3' (F) and 5'-TCCAAAAT GATCTGTCTTTCCCCT-3' (R); rat Nkrplf, 5'-AAGAGTC TATGGTAATGTAAAGACA-3' (F) and 5'-CATTCTAG TATGGCTGATCTCC-3' (R); rat Nkrplg, 5'-TGCAC

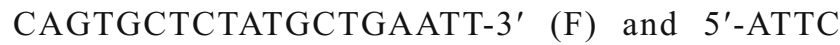
CAGTGCAAATGCCAATCTCT-3' (R); rat Cd45, 5'CGGGGTTGTTCTGTGCTCTGTTC-3' (F) and 5'CTTTGCTGTCTTCCTGGGCTTTGT-3' (R); mNkrpla, 5'-GCCTGTCGGTGCCCACGTTC-3' (F) and 5'-ACCCA CATAGTTGCTCAGGGTTTCA-3' (R); mNkrp 1c, 5'GCCTGTCGGTGCCCACGTTC-3' (F) and 5'-AGATG GAGGCACAGCTGCCA-3' (R); mNkrp 1d, 5'CCCTCGCTGGCATCGGTTGG-3' (F) and 5'TGGCGGCACAGCTGCCATTT-3' (R); mNkrp 1f, 5'TCAGCCATACTAGAGTGCCCGAG-3' (F) and 5'TGCCTCTTGCTGGTCTGGGCT-3' (R); mNkrplg, 5'- 
GCTGGCATCGGGTGGCTCTG-3' (F) and 5'CAGACGTGTTTCAGTGTCTTTTGGCA-3' (R); mCd45, 5'-AAGAGGAAGGAGCCCAGAACTGT-3' (F) and 5'GCCGTGCTTTGCGTAGAGAC-3' (R). For real-time $\mathrm{PCR}$, the following primers and probes were used: mNkrplg 5'-GACTGTAATTTGAAAGGAGCCAC-3' (F), 5'-CCATTCATCCACTTCCAAACC-3' (R) and 5'FAMTGCAGAACTTCTCAAAGGGAAAAGGACA-3'TAM (probe); mPmca4 5'-AGATGTCGGGTTTGCTATGG-3' (F), 5'-GAACTGTAGGAACTTGGAAATGC-3' (R) and 5'FAM-TGACCGATGACAACTTCACCAGCA-3'TAM (probe); mCd45 5'-GACAGAGTTAGTGAATGGAG ACC-3' (F), 5'-AAAAGTTCGGAGAGTGTAGGC-3' (R) and 5'FAM-TCTGCTTTCCTTCGCCCCAGT-3'TAM (probe).

cDNA cloning, chimeric receptor constructs and transfections

The extracellular and transmembrane domains of mNKRP1G (DQ113419) and parts of the intracellular (24 aa), the transmembrane and extracellular domains of mNKR-P1F (BALB/c, identical to DQ237931) were amplified and inserted into the EMCV.SR $\alpha$ and $\mathrm{pMX}$ vectors, respectively, both containing an inverted intracellular part of mouse $\mathrm{CD} 3 \zeta$ and a 3 '-terminal FLAG-tag. The following primers were used: mNkrp $1 f$, 5'-GACTCGAGGCATCTTCT CCATCTTTCTCC-3' (F) and 5'-GATCTAGAGACATG TATCAGGGTCTTTTG (R); mNkrplg, 5'-GCATTC TAGACTCGGCTGTGCT-3' (F) and 5'-GCATTCTA $\overline{\mathrm{GA}}$ GACGTGTTTCAGTGTCT-3' (R). Transfection with EMCV.SR $\alpha$ was performed as previously detailed (Ryan et al. 2000), using $20 \mu \mathrm{g}$ of ScaI-linearized construct and a Bio-Rad GenePulser Xcell (120 V, $950 \mu \mathrm{F}, \Omega=\infty)$ followed by selection in $1 \mathrm{mg} / \mathrm{ml}$ of active G418 sulphate. A virus transduction protocol was used for pMX to improve transfection efficiency. Plat-E cells were transfected with $2 \mu \mathrm{g}$ mNKR-P1F cDNA in a pMX vector and $1 \mu \mathrm{g}$ pCLEco plasmid with FuGENE 6 (Roche, manufacturer's protocol). Virus-containing supernatants were harvested and filtrated $(0.2-\mu \mathrm{m}$ filter) on day 4 , and $1.5 \mathrm{ml}$ was transferred to $10^{5}$ BWN3G cells in $0.5 \mathrm{ml}$ RPMI 1640 supplemented with polybrene (Sigma; to a final concentration of $8 \mu \mathrm{g} / \mathrm{ml}$ ). Cells were spin-infected at $2,000 \mathrm{rpm}$ at $32^{\circ} \mathrm{C}$ for $2 \mathrm{~h}$, incubated for $2 \mathrm{~h}$ at $37^{\circ} \mathrm{C}$ and $5 \% \mathrm{CO}_{2}$, and then the transduction solution was replaced by $2 \mathrm{ml} \mathrm{cRPMI}$ followed by selection in puromycine.

The $293 \mathrm{~T}$ cells were transiently transfected with cloned mouse $\mathrm{Clr}$ constructs inserted into the EMCV. $\mathrm{SR} \alpha$ vector with an external FLAG tag (except $\mathrm{Clrd} / \mathrm{x}$ which was used without a tag in pMX) and with the previously published rat $\mathrm{Clr}$ constructs, including $\mathrm{Clr} 10$ inserted into a pBK-CMV vector containing an internal
EYFP-encoding sequence (Kveberg et al. 2009). Clr10 contains three alternative start codons, and the shortest version was used in these experiments. Transfection was performed by FuGENE $624 \mathrm{~h}$ prior to co-incubation with reporter cells. Surface expression of transfected molecules was tested by flow cytometry for EYFP or FLAG expression using mAb M2 (Sigma). The presence of an extracellular FLAG epitope on rat Clr molecules (Clr2, Clr4, Clr7 and Clr11) did not affect ligand recognition by rat NKR-P1 receptors, as judged by a comparison with $\mathrm{Clr}$ molecules containing an intracellular EYFP tag instead (Kveberg et al. 2009).

Full-length mouse Clr and Nkrplg clones were amplified from cDNA obtained from mononuclear BALB/c splenocytes by Trizol extraction, MMLV reverse transcriptase (Promega), and random hexamer primers (Fermentas), using Pwo SuperYield DNA polymerase (Roche) and the following forward $(\mathrm{F})$ and reverse $(\mathrm{R})$ primers, restriction sites underlined: mClrb (HQ875062), 5'-GCATCTCGAGTCT GAGATGTGTGTCAC-3' (F) and 5'-GGCCTCTAGAG GAAGGAAAAAAAGGAG-3' (R); mClrc (HQ875060), 5'-CCCTCGAGATGACAGCCTCACAG-3' (F) and 5'CCTCTAGAGCACTGTAACATATAGTTGC-3' (R); mClrf (HQ875061), 5'-GCATCTCGAGTCACAGATGAA TGCTGCAA-3' (F) and 5'-GGCCTCTAGACACAT GCCTTGGTAC-3' (R); mClrg (identical to NM_020257), 5'-GCATCTCGAGCCTCCCATGCCAGATTG-3' ${ }^{-}$(F) and 5'-GCATTCTAGAGACAGGAGGAGTTTGGCA (R); mNkrplg (JF429832), 5'-TCTCCCATCTCTAATGGAT GC-3' (F) and 5'-CAGATCTGGCGTGAATAGTGA-3' (R). $\mathrm{Clrd} / \mathrm{x}$ was previously cloned from mouse $\mathrm{C} 57 \mathrm{BL} / 6$ spleen cells (Aust et al. 2009). Clra (identical to AF320600S1) was a generous gift from NOVO Nordic and was amplified from vector with the following primers: 5'-GACTCGAGAC CATGCTGAAAACCGACCTGA-3' (F) and 5'-AGTCTA GAGCCAGGGTTCACGATCAGAG-3' (R).

Reporter cell stimulation

Reporter cells, $5 \times 10^{4}$, and $5 \times 10^{4}$ stimulator cells were resuspended in RPMI 1640 supplemented with HEPES, $5 \% \mathrm{FBS}$, antibiotics and $2 \mathrm{ng} \mathrm{PMA} / \mathrm{mL}$, spun down and incubated overnight at $37^{\circ} \mathrm{C}$ in round-bottomed, 96-well microtiter plates $(100 \mu \mathrm{L} /$ well $)$. PMA $(2 \mathrm{ng} / \mathrm{ml})$ was added to the medium to enhance the specific reporter cell signal without increasing the non-specific background signal. Duplicate samples were mixed into one tube and analysed for induction of enhanced green fluorescent protein (EGFP) expression by flow cytometry (FACSCalibur, Beckton Dickinson). All target cells were excluded from the analysis by pre-labelling with SNARF-1 (Molecular Probes, Invitrogen) according to the manufacturer's protocol. 


\section{Results and discussion}

Nkrplg is mainly expressed by the Ly49s $3^{+}$NKR-P1B NK cell subset in rats

Previous studies in PVG strain rats have demonstrated that the majority of splenic NK cells are comprised of two complementary subsets of NK cells, one expressing the NKR-P1B receptor and the other the Ly49s3 receptor (Kveberg et al. 2006a). cDNA was retrieved from sorted, single-positive NKR-P1B ${ }^{+}$Ly49s $3^{-}$and Ly49s $3^{+}$NKR$\mathrm{P} \mathrm{B}^{-} \mathrm{NK}$ cells $\left(\mathrm{NKR}-\mathrm{P} 1 \mathrm{~A}^{+} \mathrm{CD} 3^{-}\right.$), and the distribution of various Nkrpl transcripts was evaluated by RT-PCR using locus-specific primers. Nkrplb was mainly detected in the NKR-P1B ${ }^{+}$cells, confirming the purity of the sorted cells. A striking finding was the almost exclusive expression of Nkrp1g in the Ly49s3 ${ }^{+} \mathrm{NK}$ subset. This non-overlapping expression pattern of $N k r p 1 b$ and $N k r p 1 g$ was confirmed by staining with a novel NKR-P1G-specific mAb (unpublished results) and is not specific for the PVG strain as it was also observed in AO strain rats. AO is closely related to PVG in the NKC and expresses the same allelic variant of Nkrplb, which is stained by mAb STOK27 (Kveberg et al. 2006a, b). Nkrp1f, on the other hand, was expressed in both the NKR-P1B ${ }^{+}$and $\mathrm{Ly}_{49} 3^{+}$subsets, but with a slight skewing towards the latter (Fig. 1a). The data indicate that the two inhibitory NKR-P1 receptors, i.e. NKR-P1B and NKR-P1G are expressed by two complementary subsets of rat NK cells, with NKR-P1G expression being concentrated in the
Ly $49 \mathrm{~s} 3^{+} \mathrm{NK}$ subset. In contrast, the activating NKR-P1A and NKR-P1F receptors are expressed by most rat NK cells across the two subsets.

Nkrplg (mNkrplg) is expressed by NKR-P1D ${ }^{-}$ and NKR-P1D ${ }^{+} \mathrm{NK}$ cells in $\mathrm{C} 57 \mathrm{BL} / 6$ mice

The rat and mouse Nkrplb genes appear to be functional homologs, and mNkrpld is an allele of mNkrplb (Carlyle et al. 2006). In both species, these receptors recognize the most telomeric Clr molecule, named Clrb in the mouse and Clr11 in the rat. NKR-P1D positive and negative NK cells (NKR-P1C ${ }^{+} \mathrm{CD}^{-}$) were sorted from C57BL/6 spleen cells stained with the 2D9 anti-NKRP1D mAb (Aust et al. 2009). The purity of the sorted cells was $>85 \%$ (data not shown). Nkrpld was detected in the NKR-P1D ${ }^{+}$fraction confirming the purity of the sorted cells, while Nkrpla, Nkrplc and Nkrplf were equally expressed by both subsets. mNkrplg was expressed by both NKR-P1D and NKR-P1D ${ }^{+}$cells, and the difference between the subsets appeared to be small, but with a slight skewing towards the NKR-P1D ${ }^{+}$subset. By contrast, a real-time PCR analysis suggested that expression of mNkrplg, when compared with $C d 45$ or the house keeping gene Pmca4, was slightly enhanced in the NKR-P1D ${ }^{-}$subset (data not shown), which would be concordant with the situation in the rat. Determination of its precise distribution on mouse NK cells will have to await the generation of a specific staining reagent.
A)

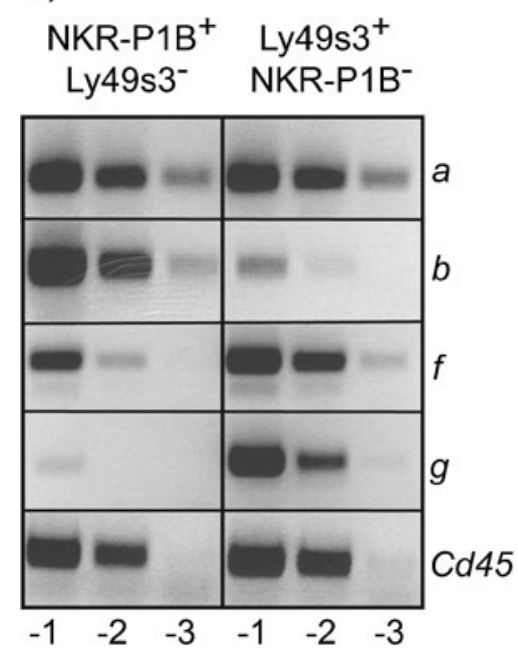

Fig. 1 Expression of Nkrplf and Nkrplg in NK cell subsets in PVG$R T 7^{b}$ rats and $\mathrm{C} 57 \mathrm{BL} / 6$ mice. a Sorted single-positive NKR${\mathrm{P} 1 \mathrm{~B}^{+} \text {Ly49s3 } 3^{-} \text {and Ly49s } 3^{+} \text {NKR-P1B }}^{-}$NK cells (CD3 ${ }^{-}$NKR-P1A ${ }^{+}$) from spleens of $\mathrm{PVG}-R T 7^{b}$ rats were analysed for expression of the indicated Nkrpl transcripts by semi-quantitative RT-PCR, performed at tenfold dilutions. Cd45 was used to normalize cDNA concentration
B)

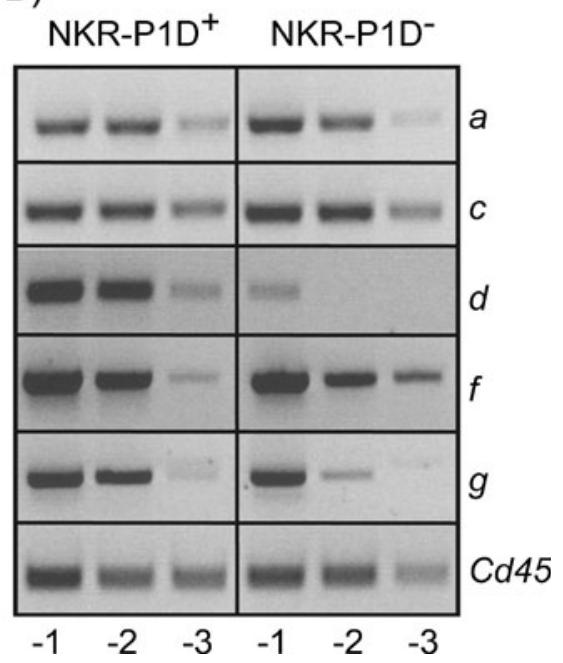

from the two subsets. Note that expression of Nkrplg is confined to the Ly49s $3^{+}$NK subset, while Nkrplf is present in both subsets. b Sorted NKR-P1D ${ }^{+}$and NKR-P1D ${ }^{-}$NK cells $\left(C D 3^{-} \mathrm{NKR}^{-P} 1 \mathrm{C}^{+}\right)$from spleens of C57BL/6 mice were analysed for expression of the indicated Nkrpl transcripts. Cd45 was used to normalize cDNA concentration from the two subsets 
Rat and mouse NKR-P1F and NKR-P1G reporter cells react with an overlapping panel of tumour target cells

We used the BWN3G reporter cell system which allows visualization of ligand binding by transcription of EGFP upon incubation with stimulator cells. During the course of these studies, we noted that the rat NKR-P1G reporter (Kveberg et al. 2009) reacted strongly with mouse stimulator cells. To systematically evaluate xenoreactivity by NKR-P1F and NKR-P1G, we generated FLAG-tagged reporters also for the mouse equivalents. Surface expression of NKR-P1 molecules on reporter cells is shown in Fig. 2a. A collection of rat and mouse tumour cell lines was tested for their stimulatory properties. Both rat and mouse NKR$\mathrm{P} 1 \mathrm{~F}$ and $\mathrm{G}$ reporters were promiscuous and reacted with most rat target cells (Fig. 2b), with the exception of the NK cell line RNK16 which was recognized mainly by the NKR-P1F reporters. This might be related to the fact that RNK-16 cells express the strong NKR-P1F ligand Clr4 (Flornes et al. 2010).

In general, the mouse reporters responded more firmly to rat stimulator cells than their rat counterparts. The opposite was the case when using NKR-P1G reporters and mouse target cells (Fig. 2c). While mNKR-P1G responded only to NS0 and EL-4, rat NKR-P1G showed robust responses to Ltk, P388.D1, NS0, EL-4 and YAC and a weak response to RMA-S. mNKR-P1F reacted with the same target cells as rat NKR-P1G. While it is difficult to correlate reporter stimulation with expression of individual Clrs, the redundancy in target cell recognition corresponds well with the
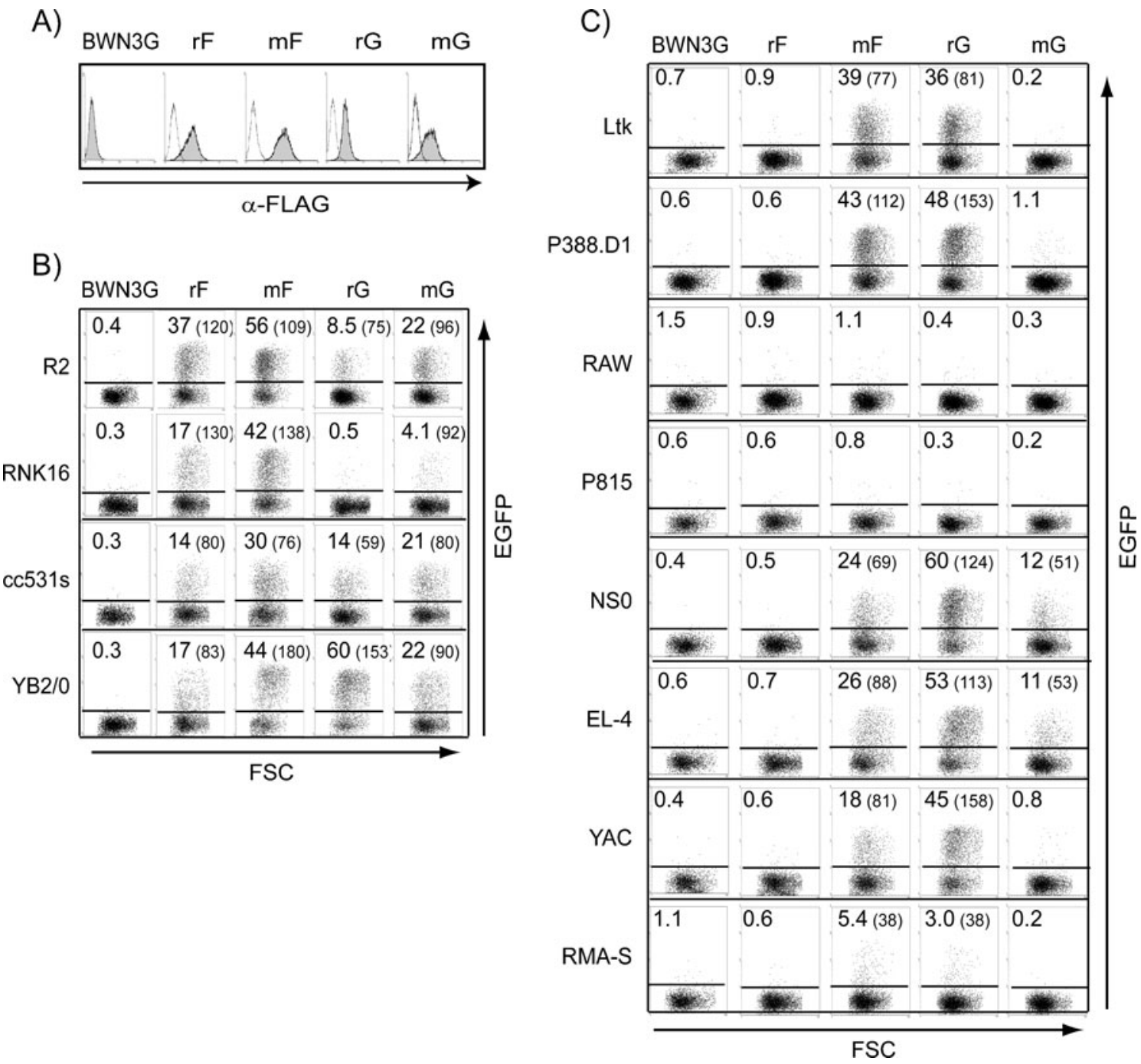

Fig. 2 Rat and mouse NKR-P1F and NKR-P1G reporters show overlapping specificities against a panel of tumour target cells. a Expression of FLAG-tagged chimeric molecules was detected by staining with the anti-FLAG mAb, M2 (shaded histograms). Open histograms show control staining with only secondary antibody.

Reporter cells ( $r$ rat and $m$ mouse) were co-incubated overnight with rat $\mathbf{b}$ or mouse $\mathbf{c}$ tumour cell lines. Ligand-induced stimulation of chimeric receptors was measured as an EGFP signal by flow cytometry. Numbers represent percentage and MFI values (in parenthesis) of positive cells. One out of three representative experiments is shown 
promiscuity in Clr ligand binding observed below. Rat NKR-P1F did not react with any of the mouse stimulators but responded well with mouse Clrc and Clrg when expressed in $293 \mathrm{~T}$ cells (see below). This suggests that endogenous Clr ligands must be expressed at a sufficiently high level for efficient reporter stimulation, and that this threshold was not reached by the mouse tumour cells in combination with the rat NKR-P1F reporter.

The orthologous NKR-P1F and NKR-P1G receptors in rats and mice show a striking conservation of specificity for $\mathrm{Clr}$ ligands

Mouse Clr molecules were transiently expressed in 293T cells and tested for their stimulatory properties, together with the rat $\mathrm{Clr}$ transfectants previously described, including Clr10 (Kveberg et al. 2009). Our analysis included six of the seven functional $\mathrm{Clr}$ genes existing in the C57BL/6 genome, including $\mathrm{Clrc}$ which has not been previously isolated at the cDNA level, corresponding with the predicted mRNA of the Clec $2 f$ gene. A schematic representation of this part of the mouse NKC and a conversion table of the $\mathrm{Clr}$ and $\mathrm{Clec} 2$ nomenclature are given in Fig. 3a, b. Surface expression of FLAG-tagged mouse Clr molecules was verified by staining with an anti-FLAG (Fig. 3c). While the Clrg and Clrd/x transfectants induced brisk EGFP responses in both the rat and mouse NKR-P1F and NKR-P1G reporters, Clrc and Clrf specifically stimulated the NKR-P1F and NKR-P1G reporters, respectively (Fig. 3d). The results confirmed the previously reported interactions of mNKR-P1F with Clrg (Iizuka et al. 2003) and $\mathrm{Clrd} / \mathrm{x}$ (Aust et al. 2009), and in addition, identified Clrc as a novel ligand for mNKR-P1F and Clrf, Clrg, and Clrd/x for NKR-P1G. It should be noted that Clrc, which is located next to NKR-P1F in the genome, is preferentially recognized by this receptor, and the same is true for Clrf and NKR-P1G. The lack of response towards Clrb was as expected since this molecule is the ligand of mNKR-P1B/D (Carlyle et al. 2004; Iizuka et al. 2003). Clra was not recognized by any of our reporter cell lines.

Most rat Clr transfectants, with the exception of Clr10 and Clr11, induced a brisk EGFP signal in the rat and mouse NKR-P1F reporters (Fig. 3e). Stimulation of the NKR-P1G reporters was more restricted and limited to Clr2, Clr6 and Clr7 while Clr4 stimulated the mNKR-P1G reporter only. This difference is probably quantitative rather than qualitative, as Clr4 induced a weak positive response by rat NKR-P1G when using a more sensitive LacZ-based reporter cell line (data not shown).

Relatively low levels of expression were observed for Clrf, Clra and Clr10 in 293T cells (Fig. 3 and Kveberg et al. 2009), which constitute a separate phylogenetic clade with
Clrf and Clra being orthologs of Clr9 and Clr10, respectively. Their low expression levels might be related to some structural properties or to expression programs common to this group. The fact that Clrf was effective in stimulating the NKR-P1G reporters suggests that the negative results obtained for the two orthologs Clra and Clr10 are related to conserved biological properties and not to limitations of the reporter assay (Fig. 3b). The result also predicts that $\mathrm{Clr} 9$ is recognized by NKR-P1G, but this assumption could not be tested as attempts to clone Clr9 have been unsuccessful.

The striking promiscuity in ligand recognition displayed by the xenoreactive NKR-P1F and NKR-P1G receptors suggests that the influence of allelic variation is of less importance. Variation appears to be very limited at the receptor level, with NKR-P1F being identical at the protein level between the $\mathrm{C} 57 \mathrm{BL} / 6$ and $\mathrm{BALB} / \mathrm{c}$ strains, while NKR-P1G shows a conservative substitution of its terminal amino acid only (Nkrplg from BALB/c amplified as specified in "Materials and methods"). No allelic differences have, to date, been observed for the rat NKR-P1F and NKR-P1G receptors, with identical sequences being derived from NKC-deviant PVG and DA or BN strains (Kveberg et al. 2006b, 2009). Allelic differences also appear to be limited at the level of the ligand, both in the rat (Kveberg et al. 2009) and the mouse. Clrb, Clrc and Clrg are identical in $\mathrm{C} 57 \mathrm{BL} / 6$ and $\mathrm{BALB} / \mathrm{c}$, while Clrf differs between $\mathrm{C} 57 \mathrm{BL} / 6$ and $\mathrm{BALB} / \mathrm{c}$ by only three amino acids in the extracellular region.

The rat NKR-P1A or NKR-P1B reporter cells did not respond to any of the mouse tumour targets or mouse $\mathrm{Clr}$ transfectants, only to rat Clr11 (data not shown). This suggests that xenoreactivity is a unique property of the distal cluster of NKR-P1 receptors in the rat and of their mouse orthologs, i.e. NKR-P1F and NKR-P1G. Preservation of ligand-binding specificities supports the notion that the two receptors were present before speciation of rats and mice in a common rodent ancestor (Kveberg et al. 2009).

\section{Concluding remarks}

These studies have shown that the inhibitory NKR-P1G receptor is expressed in an NK subset-specific fashion, which may be a general principle for inhibitory NKR-P1 receptors. The present data have extended our previous observation, that the NKR-P1F and NKR-P1G receptors are functionally related, sharing overlapping specificities for Clr ligands. The most striking finding was the conservation of ligand specificity between the orthologous NKR-P1F and NKR-P1G receptors in rats and mice, which explains the potent xenoreactivity observed in both ways. The interactions between the inhibitory NKR-P1 receptors and their Clr 
A)

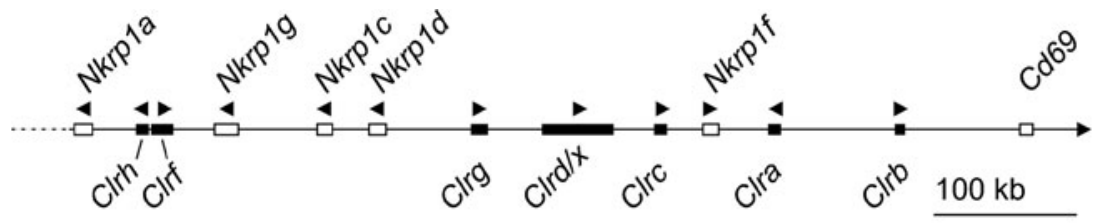

C) Clrf Clrg Clrc Clra Clrb

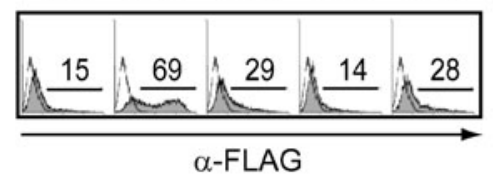

D)

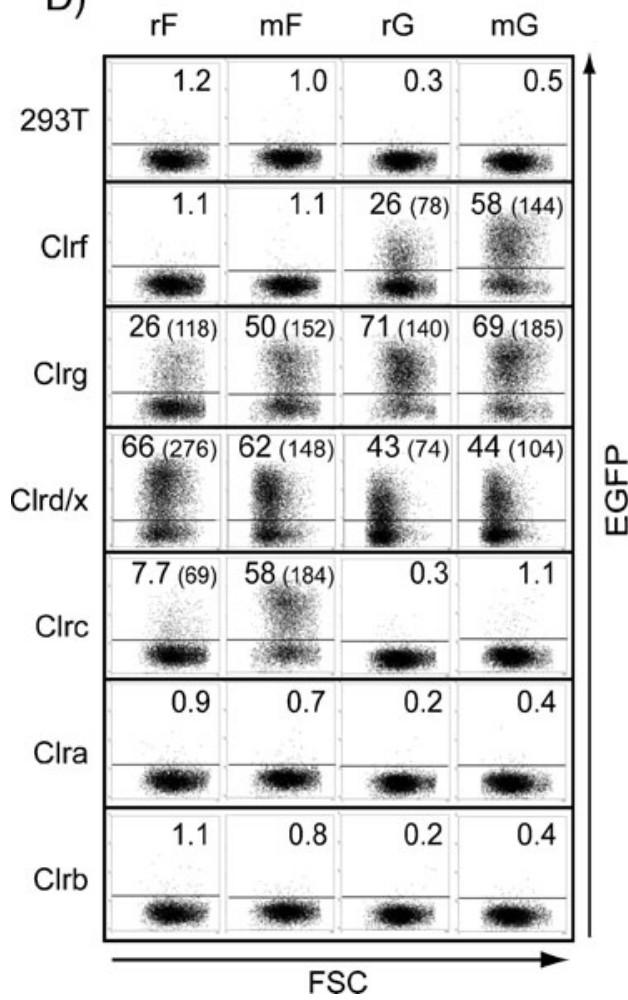

E)

E) $\quad \mathrm{rF} \quad \mathrm{mF} \quad \mathrm{rG} \quad \mathrm{mG}$
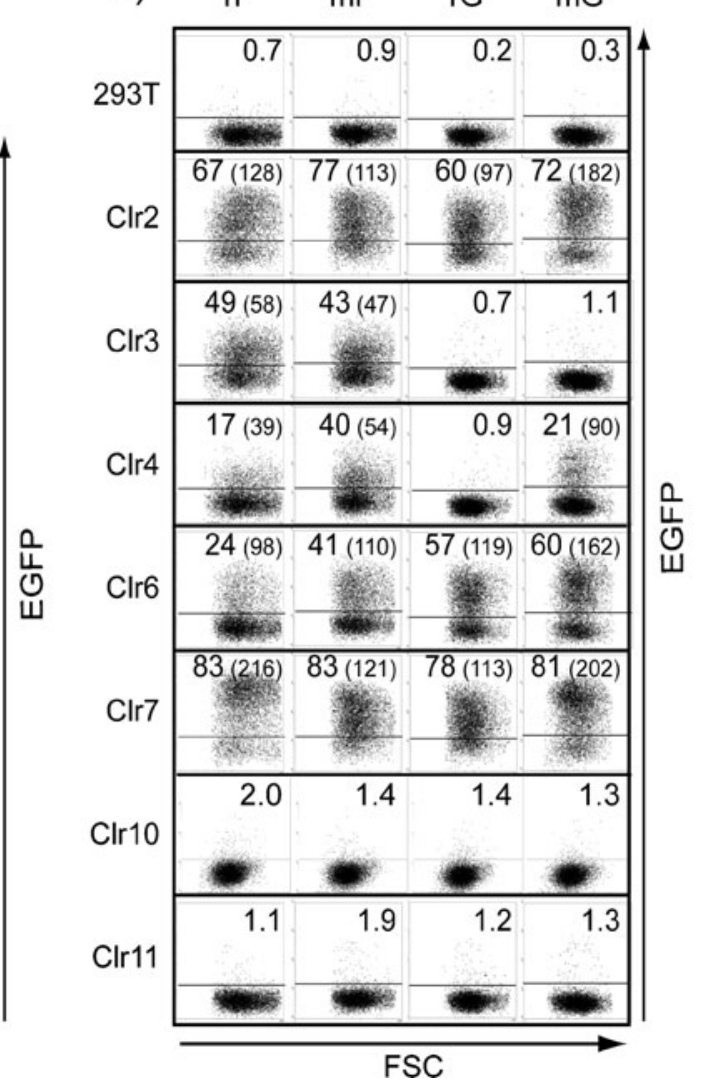

B)

\begin{tabular}{l|l} 
Clr & Clec2 \\
\hline$a$ & $e$ \\
$b$ & $d$ \\
$c$ & $f$ \\
$d / x$ & $g$ \\
$e$ & - (pseudo) \\
$f$ & $h$ \\
$g$ & $i$ \\
$h$ & $j$
\end{tabular}

F)

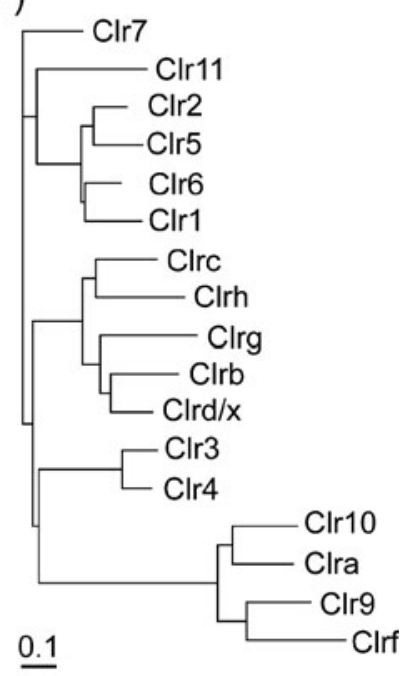

Fig. 3 Rat and mouse NKR-P1F and NKR-P1G reporters show overlapping specificities against a panel of Clr transfectants. a Schematic map of the centromeric part of the mouse NKC based on a C57BL/6J chromosome 6 genomic contig (NT 039353.7). The distance from Nkrpla to Clrb is approximately $577 \mathrm{k}$. Only functional genes are shown; the predicted mRNA sequence of Clrh has not been confirmed. b The $\mathrm{Cl} r$ nomenclature has previously been confused by erroneously assembled genomic clones. A conversion table of the suggested $\mathrm{Clr}$ and $\mathrm{Clec} 2$ nomenclature is shown. c Surface expression of the FLAG-tagged mouse Clr molecules (filled histograms) was verified by staining with $\mathrm{mAb} \mathrm{M} 2$ and flow cytometry, and staining of untransfected 293T control cells is shown as unfilled histograms. An untagged version of $\mathrm{Clrd} / \mathrm{x}$ was tested in a separate set of experiments. Reporter cells ( $r$ rat and $m$ mouse) were co-incubated overnight with 293 T stimulator cells transiently transfected with the indicated d

ligands may allow for "missing self" surveillance of neoplastic and otherwise stressed cells (Fine et al. 2010; Voigt et al. 2007). The activating receptors should also be taken into consideration since they may react with the same ligand(s) mouse and e rat $\mathrm{Clr}$ molecules and stimulation measured as an EGFP signal by flow cytometry. Numbers represent percentage and MFI values (in parenthesis) of positive cells. Transfection efficiency of the rat $\mathrm{Clr}$ constructs was verified by EYFP staining (data not shown). Clr10 was tested in a separate set of experiments. One representative out of three to five experiments is shown. $\mathbf{f}$ Phylogenetic tree based on the extracellular aa sequence of various mouse and rat Clr molecules, accession numbers given in parenthesis: Clr1 (NP_001019508), Clr2 (ABX54835), Clr3 (ACJ23591), Clr4 (ACJ23593), Clr5 (ABO15828), Clr6 (ACJ23590), Clr7 (ABX54838), Clr9 (XP 232399), Clr10 (ACJ23592), Clr11 (ABX54837), Clra (AAL̄37200), Clrb (AAK70357), Clrc (ADX42723), Clrd/x (also called ocilrp1, BAE23491), Clrf (AAK70358), Clrg (AAK70359), Clrh (XP_001480526)

(Kveberg et al. 2009). The broad reactivity patterns observed for NKR-P1F and NKR-P1G receptors suggest that they can be seen as sensors of the global status for Clr expression in cells. 
Acknowledgements This work was supported by grants from the Norwegian Cancer Society, Solveig og Ove Lunds legat and the South-Eastern Norway Regional Health Authority. We thank Christian Naper for the discussions and Stine Martinsen for the excellent technical assistance and NOVO Nordic, Copenhagen for providing Clra cDNA.

Open Access This article is distributed under the terms of the Creative Commons Attribution Noncommercial License which permits any noncommercial use, distribution, and reproduction in any medium, provided the original author(s) and source are credited.

\section{References}

Appasamy PM, Kenniston TW, Brissette-Storkus CS, Chambers WH (1996) NKR-P1 ${ }^{\mathrm{dim}} / \mathrm{TCR} \alpha \beta^{+}$T cells and natural killer cells share expression of NKR-P1A and NKR-P1D. Nat Immun 15:259-268

Aust JG, Gays F, Mickiewicz KM, Buchanan E, Brooks CG (2009) The expression and function of the NKRP1 receptor family in C57BL/6 mice. J Immunol 183:106-116

Carlyle JR, Jamieson AM, Gasser S, Clingan CS, Arase H, Raulet DH (2004) Missing self-recognition of Ocil/Clr-b by inhibitory NKR-P1 natural killer cell receptors. Proc Natl Acad Sci USA 101:3527-3532

Carlyle JR, Mesci A, Ljutic B, Belanger S, Tai L-H, Rousselle E, Troke AD, Proteau M-F, Makrigiannis AP (2006) Molecular and genetic basis for strain-dependent NK1.1 alloreactivity of mouse NK cells. J Immunol 176:7511-7524

Fine JH, Chen P, Mesci A, Allan DSJ, Gasser S, Raulet DH, Carlyle JR (2010) Chemotherapy-induced genotoxic stress promotes sensitivity to natural killer cell cytotoxicity by enabling missing-self recognition. Cancer Res 70:7102-7113

Flornes LM, Nylenna Ø, Saether PC, Daws MR, Dissen E, Fossum S (2010) The complete inventory of receptors encoded by the rat natural killer cell gene complex. Immunogenetics 62:521-530

Giorda R, Rudert WA, Vavassori C, Chambers WH, Hiserodt JC, Trucco M (1990) NKR-P1, a signal transduction molecule on natural killer cells. Science 249:1298-1300

Iizuka K, Naidenko OV, Plougastel BFM, Fremont DH, Yokoyama WM (2003) Genetically linked C-type lectin-related ligands for the NKRP1 family of natural killer cell receptors. Nat Immunol 4:801-807
Kveberg L, Bäck CJ, Dai K-Z, Inngjerdingen M, Rolstad B, Ryan JC, Vaage JT, Naper C (2006a) The novel inhibitory NKR-P1C receptor and Ly49s3 identify two complementary, functionally distinct NK cell subsets in rats. J Immunol 176:4133-4140

Kveberg L, Dai K-Z, Dissen E, Ryan JC, Rolstad B, Vaage JT, Naper C (2006b) Strain-dependent expression of four structurally related rat Ly49 receptors; correlation with NK gene complex haplotype and NK alloreactivity. Immunogenetics 58:905-916

Kveberg L, Dai K-Z, Westgaard IH, Daws MR, Fossum S, Naper C, Vaage JT (2009) Two major groups of rat NKR-P1 receptors can be distinguished based on chromosomal localization, phylogenetic analysis and Clr ligand binding. Eur J Immunol 39:541-551

Kveberg L, Jiménez-Royo P, Naper C, Rolstad B, Butcher GW, Vaage JT, Inngjerdingen $M$ (2010) Two complementary rat NK cell subsets, Ly49s $3^{+}$and NKR-P1B ${ }^{+}$, differ in phenotypic characteristics and responsiveness to cytokines. J Leukoc Biol 88:87-93

Naper C, Dai K-Z, Kveberg L, Rolstad B, Niemi EC, Vaage JT, Ryan JC (2005) Two structurally related rat Ly49 receptors with opposing functions (Ly49 stimulatory receptor 5 and Ly49 inhibitory receptor 5) recognize nonclassical MHC class Ibencoded target ligands. J Immunol 174:2702-2711

Naper C, Ryan JC, Kirsch R, Butcher GW, Rolstad B, Vaage JT (1999) Genes in two major histocompatibility complex class I regions control selection, phenotype, and function of a rat Ly-49 natural killer cell subset. Eur J Immunol 29:2046-2053

Plougastel B, Dubbelde C, Yokoyama WM (2001) Cloning of Clr, a new family of lectin-like genes localized between mouse Nkrp1a and Cd69. Immunogenetics 53:209-214

Ryan JC, Niemi EC, Nakamura MC (2000) Functional analysis of natural killer cell receptors in the RNK-16 rat leukemic cell line. Methods Mol Biol 121:283-295

Vance RE, Kraft JR, Altman JD, Jensen PE, Raulet DH (1998) Mouse CD94/NKG2A is a natural killer cell receptor for the nonclassical major histocompatibility complex (MHC) class I molecule Qa- ${ }^{\mathrm{b}}$. J Exp Med 188:1841-1848

Voigt S, Mesci A, Ettinger J, Fine JH, Chen P, Chou W, Carlyle JR (2007) Cytomegalovirus evasion of innate immunity by subversion of the NKR-P1B:Clr-b missing-self axis. Immunity 26:617-627

Yokoyama WM, Plougastel BFM (2003) Immune functions encoded by the natural killer gene complex. Nat Rev Immunol 3:304316 